\title{
Extended Reality and the Future of Architecture
}

\author{
Karol Wysznacki \\ Lodz University of Technology
}

\begin{abstract}
The aim of the paper is to present how the augmented reality technology can affect the future of architecture. Firstly I will try to explain what does 'augmented reality' mean and give a few examples of the technology being researched by major companies around the world. Secondly I will present how s-f movie directors imagine the development of the idea. "Her", "Cloud atlas" or even the famous "Matrix" convey visions of this technology being used in an architectural way. Can these visions come true? How can the technology influence the way we perceive space? Thirdly we will analyse philosophical, moral and religious aspects of the technology. Especially George Berkeley's philosophy seems to give an interesting clue in its interpretation. We will also research ideas by one of the most famous polish s-f novelists, Stanislaw Lem.
\end{abstract}

Keywords: Augmented reality, virtual reality, architecture, science-fiction, philosophy, future, vision, cinema, movie, computer graphics.

\section{Augmented Reality}

When we discuss the influence, that augmented reality can have on the subject of architecture, we should firstly explain the most important definition, that will be used in the article. Augmented reality - according to Ivan Sutherland - can be discussed only if we meet three conditions; firstly we connect virtual space with the real one, secondly - we feel real time interactivity and thirdly the discussed space is three-dimensional [1]. Speaking more clearly, augmented reality is where the digital, virtual world meets the real space on one interactive display.

Although the general idea of the augmented reality dates back to the sixties, it was not until nineties when "Boeing" made use of it in a first ever commercial project. Special displays were used to help technical crew find orientation in very complex mechanisms of their products [1].

Nowadays there are multiple companies developing their own augmented reality devices; this include Google (Google glass), Sony (SmartEyeglass) and Microsoft (Microsoft Hololens). Google Glass was even on the market for an extremely short time period, however the first version of the product is not said to be a giant commercial success. Despite that, according to some internet sources, a new version of the device is going to be presented soon. As we can see the trend for implementation of augmented reality technology is growing rapidly and in a forthcoming years we can expect at least a few augmented reality devices. These will surely get hundreds of applications and among them - as we can expect - there will be a few connected with architecture. In this article I will try to discuss how can they influence a life of an architect and - what I find even more important - how can they influence the life of people, who use the buildings created by architects - that means all of us.

\section{Augmented Reality and Architecture}

The use of augmented reality in an architectural field is usually connected with the implementation of new CAD (Computer Aided Design) software. The early versions of such an application already exist; during the presentation of Microsoft Hololens the audience was shown in real time how a girl uses the device to model a quadcopter (which was even printed in 3D). Although the interface seemed a little bit childish and surely could not be regarded as a tool for professional architects, the general idea is very interesting. The ability to see virtual building in the context or to model an interior while actually being in its virtual representation is a fulfilment of the wildest architectural dreams.

The idea of using virtual reality in the process of architectural design is not new and has been researched for a long time. For example in Bydgoszcz, Poland there has been a research on using a model of Cave Automatic 
Virtual Environment in the process of building creation [2]. Although the system of "direct design" was, in my opinion, very promising, it had one major drawback - building CAVE, which consists of multiple 3d projectors, movement sensors and needs a large free space has to be very expensive, far beyond the financial possibilities of ordinary people.

With the implementation of latest technology the idea of designing while actually "being in the virtual world" will hopefully be available to everybody. When we look backwards - it was the moment when computers become small and affordable was the real start of an era of information. I hope that what we will be soon stepping into is an era of augmented reality design.

How will it look like? What threats can we expect? Which philosophical questions will we meet? On the following pages we are going to analyse these questions, taking into consideration the context of science fiction movies, in which augmented reality has already been seen decades ago.

\section{Augmented Reality, Architecture and S-F Movies}

The search for the earliest examples of augmented reality in s-f movies is not the purpose of this article, however we should mention that holographic projectors probably were the first augmented reality devices to make their way to the big screen. They were visualised in "Star Wars", "Star Trek" and many other productions after Dennis Gabor created the scientific background of the technology in 1947.

The visions of augmented reality have changed a lot since that time. Digital holograms in s-f movies are no longer monochrome ("Star Wars") or need a special room - holodeck ("Star Trek"), but are usually presented in perfect quality in the flats of movie characters. Theodore Twombly ("Her" by Spike Jonze, 2014) does not need any special glasses to play an augmented reality game, which makes him forget about loneliness. Hae Joo-Chang ("Cloud Atlas" by Tom Tykwer, Lana and Andy Wachowsky, 2012) with just a few gestures makes the augmented reality system dramatically change the room where he lives.

A giant change can be visible when we take into consideration the purpose, for which movie characters use the augmented reality devices. In the present movies augmented reality is no longer used for communication purposes or scientific research; often we can see that the devices shape the virtual environment in a beautiful way just to please the movie characters.

This is an interesting paradox - in the futuristic visions virtual architecture takes place of the real one; the real one does not have to be pretty, because finally it will be mapped with $3 \mathrm{~d}$ virtual renderings. If this would be possible (perhaps with the implementation of devices I have already presented it can come true soon), we will face multiple dilemmas, for example: buy an expensive, beautiful chair or just a simple one and then use special eyewear to perceive it as a very exclusive product? Hire an interior architect or just CG artist, who will design a beautiful "interface" for our life? Change our furniture or just re-render everything with just a click of a button? Taking into account the costs, second option may be tempting for many people.

\section{Augmented Reality, Architecture, S-F Movies and Philosophical Questions}

A vision presented in the previous paragraph can be regarded as beautiful, but we have to take into consideration that computer renderings that will be perceived as parts of the real world may finally lead to our disruption. A virtual chair will not hold our body, when we sit on it. A virtual friend with who we play chess will not help us, when we fall into trouble.

S-f cinema gave us also many examples in which virtual worlds were used as a prison for people; these include "The thirteenth floor" (Josef Rusnak, 1999) or "The Matrix" (Larry and Andy Wachowsky, 1999). Much earlier - in 1957 - similar visions were created in a "The star diaries" - a collection of short stories by Stanislaw Lem [3].

The tales in which people did not know that all their life was a computer generated reality can, in my opinion, be analysed in the context of platonic cave, which, by the way, gave the name to the, mentioned earlier, "Cave Automatic Virtual Environment". Just like in the famous example from Plato's "Politea" people who spent 
all their lives in a certain environment (cave - virtual world) may not know about the existence of anything else [4]. However, are we sure, that virtual or augmented reality is just the imperfect reflection of the material one? What makes the "material" architecture better than the "digital" one?

We can go even a little bit further - what does it mean, that something is "real"? Is it the truth that only material substance can be regarded as the "real" one? Maybe it is just one of the possible interfaces for us to interact with the world. Maybe moving from "real" buildings to the "augmented reality" space is just like changing the operating system in the computer - the old, physical interface is just no longer suitable for the people of 21 st century.

Moreover, are we sure that, what we call matter, really exists? Maybe the way we perceive the world was just programmed into our brains by a divine creature? Maybe only our souls are real and everything around us is just a vision? Similar ideas where sometimes presented by idealistic philosophers, for example George Berkeley, who wrote:

I do not argue against the existence of any one thing that we can apprehend, either by sense or reflection. That the things I see with mine eyes and touch with my hands do exist, really exist, I make not the least question. The only thing whose existence we deny, is that which philosophers call matter or corporeal substance. And in doing of this, there is no damage done to the rest of mankind, who, I dare say, will never miss it. [5]

\section{Summary}

To sum up, as predicted in s-f movies, in a few years time we will have an opportunity to buy the devices, which may change our perception of space, letting us see digital holograms as a part of real world. This may change not only the process of design, but also lead to the possibility of changing the "real" architecture to a "virtual" one. It is hard to tell if the consequences of this will be positive or negative, however, it certainly will make us face one of the most important philosophical questions - "What is the truth?".

\section{References}

[1] M. Synowiec, "Zasada działania i wybrane zastosowania poszerzonej rzeczywistości," Szybkobieżne Pojazdy Gaqsiennicowe, vol. 29, pp. 1-10, January 2012.

[2] A. Asanowicz, "Systemy rzeczywistości wirtualnej w architekturze," Architecture et Artibus, vol 4/2012, pp. 5-12, April 2012.

[3] S. Lem, "The Star Diaries," New York, U.S. : Mariner Books, 1985.

[4] Plato, "Politeia," New York, U.S. : Dover Publications., 2000

[5] G. Berkeley, "Principles of Human Knowledge," Radford, U.S. : Wilder Publications, 2009 